DOI 10.37882/2500-3682.2022.01.13

\title{
К ПРОБЛЕМЕ СТАНОВЛЕНИЯ СОЦИАЛЬНОЙ ФИЛОСОФИИ ХХ ВЕКА: МАРКСИСТСКАЯ РЕКОНСТРУКЦИЯ ИСТОРИИ
}

\section{ON THE PROBLEM OF THE FORMATION OF SOCIAL PHILOSOPHY OF THE XX CENTURY: A MARXIST RECONSTRUCTION OF HISTORY}

\section{Smetankina A. Ryabov}

Summary: The article is devoted to the problem of the specifics of the reconstruction of history in the social philosophy of Marxism, both at the stage of Karl Marx's search for evidence of the incorrectness of the speculative method in the structure of Hegel's "Philosophy of Law» in relation to the specifics of social relations, and in the perspective of incorporating historical facts into the system of ideas about inequality in the social structure ... Marx in «To the Critique of Hegel's Philosophy of Law» criticizes the very method of synthesis of contradictions of equal quality, while one of the sides of the contradiction is objective, and is not «removed», but deepens with the help of genetic analysis. So, to prove the historical reasons for the alienation of civil rights, Marx reveals the relationship between forms of property and political institutions, the facts of the dependence of the forms of social structure on the economic structure, systematizing them in the "Kreuznach notebooks», which are historical studies with final generalizations of a philosophical nature. Historical research alternates in the "Kreutznach notebooks» with criticism of the contradictions of Rousseau's concept. The categorical apparatus of history reconstruction is also changing. In the course of his work with historical works, Marx eventually turns to the study of the structure of civil society, rejecting the idea of a social contract.

Keywords: method, socio-philosophical system, social values, social relations, historical process.

\section{Сметанкина Людмила Васильевна}

Ә.ф.н., ФГКВОУ ВО «Военная орденов Жукова и Ленина Краснознаменная академия связи имени Маршала Советского Союза С.М. Буденного» Министерства обороны Российской Федерации Ismetankina.umo@mail.ru

Рябов Александр Вячеславович К.культурологии, доцент, ФГБОУ ВО «СанктПетербургский университет Государственной противопожарной службы Министерства Российской Федерации по делам гражданской обороны, чрезвычайным ситуациям и ликвидации последствий стихийных бедствий» ryboff@yandex.ru

Аннотация: Статья посвящена проблеме специфики реконструкции истории в социальной философии марксизма, как на стадии поиска К. Марксом доказательств некорректности спекулятивного метода в структуре «Философии права» Гегеля применительно к специфике общественных отношений, так и в перспективе инкорпорирования исторических фактов в систему представлений о неравенстве в социальной структуре. Маркса в «К критике Гегелевской философии права» подвергает критике сам метод синтеза равнокачественных противоречий, тогда как одна из сторон противоречия является предметной, и не «снимается», а углубляется с помощью генетического анализа. Так, для доказательства исторических причин отчуждения гражданских прав Маркс выявляет отношения форм собственности и политических институтов, факты зависимости форм общественного устройства от экономической структуры, систематизируя их в «Крейцнахских тетрадях», которые представляют собой исторические исследования с итоговыми обобщениями философского характера. Исторические исследования чередуются в «Крейцнахских тетрадях» с критикой противоречий концепции Руссо. Изменяется и категориальный аппарат реконструкции истории. В ходе работы с историческими произведениями Маркс, в итоге, переходит к изучению структуры гражданского общества, отвергая идею общественного договора.

Ключевые слова: метод, социально-философская система, социальные ценности, общественные отношения, исторический процесс.

Историк с неизбежностью совершал операцию системной оценки социального феномена, превращаемого им в факт. С другой стороны, задавая меру социально значимого, историк тем самым задавал масштаб социального времени в границах его концепции. К тому же историческое исследование - это и процедура сопоставления модели исторического прогресса, принятой историком за рабочую в данном конкретном случае, с другими, устанавливаемыми в других сферах гуманитарного знания.

Например, в работе «История Флоренции», изучавшегося К. Марксом Никколо Макиавелли, историографы 
выделяют особо концепцию оценки исторических фактов, в частности, мысль о связи явлений внутренней и внешней политики, тезис о невозможности для субъекта истории предвидеть последствия своей деятельности, трактовку истории как естественного процесса [1, с. 59].

История, таким образом, как раздел гуманитарного знания, ни в коей мере не являлась, как это пытался представить, например, Л. Ранке, описательной, собирательной, фактофиксирующей дисциплиной, а выступала в ранге науки о человеке в его мире, создавая концепцию мира и человека. Эта особенность исторического знания - структурировать актуальную бесконечность фактов - являлась важнейшим признаком, по которому оно включалось в философское в качестве его необходимого элемента.

В домарксистской историографии по мере ее становления обнаруживались и укреплялись две тенденции: I) отделение ценностного аспекта исторического исследования как специфического признака гуманитарного знания в отличие от естественнонаучного (Г. Риккерт); 2) тенденция формализовать гуманитарное знание, постулируя тождественность его методики логике естественнонаучного метода (О. Конт, К. Поппер, К. Гемпель).

Обе эти тенденции были своеобразной реакцией на гегелевскую систематику. Марксизм же развивался как раз из самого исторического знания. Генетический анализ - неотъемлемый аспект любого марксистского исследования. Поэтому социология, теория права, политэкономия - не рядоположенные, а системные элементы, имеющие одно и то же базовое основание - науку о человеке как в его общественных отношениях, так и в истории их становления до статуса элементов общественного целого.

Началом этого движения к интеграции элементов гуманитарного знания в единую позитивную науку о человеке можно считать критику Марксом спекулятивного метода Г. Гегеля в структуре «Философии права».

Основой для систематизации всей совокупности общественных явлений для Гегеля является замкнутое в логический круг описание моментов синтеза противоречий, субстратом которых служит вся культура. Принцип развития в философии Гегеля работает как центральный метод конструирования понятий, и чем больше в это формообразование втягивается реальная история и общественная жизнь, тем труднее этот метод применять, поскольку для фиксации специфики общественных отношений требуются другие понятия и другой метод их конструирования (специфическая логика специфического предмета).

Маркс формирует принцип развития, фиксируя про- тиворечивость правовых отношений буржуазного общества и обращаясь к их генетическому анализу. Поэтому работу «К критике гегелевской философии права» можно считать развернутым процессом методологической реконструкции, в ходе которой обнаруживаются конструктивные элементы будущей системной связи марксистской науки об обществе. Начав критику философии права с доказательства методологической некорректности подведения всей совокупности знаний под схему синтеза равнокачественных противоречий в объединяющем, снимающем их определении, Маркс утверждает необходимость анализа связи противоречий существования. Одна из сторон противоречия является «предметной», поэтому противоречие не снимается в синтезе, а углубляется с помощью генетического анализа.

Однако доказательство некорректности спекулятивного метода должно быть выведено за пределы идеалистической системы. В самой работе это «выведение» осуществляется в ходе выявления содержания понятия «сословие гражданского общества». Маркс пишет про то, что Гегель институт майората конституирует необходимым элементом государственного устройства, выводя пэров и родовые имения из Абсолютной Идеи. На самом же деле гражданское общество, представляемое сословиями, и государство - разорваны, и разорванность эта имеет конкретные исторические объяснения.

После этого в рукописи появляется гораздо больше исторических аргументов, и практически каждый свой тезис Маркс подтверждает историческими примерами. Для подтверждения тезиса об историческом происхождении отчуждения политических прав граждан Маркс обращается к историческим источникам. В пяти тетрадях («Крейцнахские тетради») сосредоточены выписки из двадцати пяти работ историков различных школ, хронологически охватывающих двадцать пять столетий. Характер выписок, расположение материала, аппарат, составленный Марксом к тетрадям, свидетельствуют о работе по вторичной реконструкции истории по имеющимся в наличии историческим источникам. Предвосхитив многие открытия аналитиков истории, Маркс изменил традиционные представления, сводящие историографию к добросовестному изложению документальных источников. Идеал «научности», провозглашенный Л. Ранке в качестве цели исторического исследования, был повторением, только на другом уровне, гегелевского тезиса о разумности действительности.

Для Маркса описание истории есть одновременно и ее оценка с определенных социальных позиций. Историческое исследование есть схема связи социально значимого и одновременная проверка ее истинности. История не есть самостоятельный предмет, поскольку историческое объяснение - всегда фрагмент социальнофилософской концепции, определенная система соци- 
альных ценностей (в данном случае система социальных ценностей «гражданина», не имеющего ни политических, ни гражданских прав).

Предметные указатели Маркса в «Крейцнахских тетрадях» позволяют выделить несколько групп проблем, разрешенных в ходе работы над историческими исследованиями. Прежде всего это рубрика «Собственность и ее следствия» из предметного указателя к I и II тетрадям. Маркс, используя работу К.Ф.Э. Людвига «История последних пятидесяти лет» и работу Ш. Лакретеля «История Франции после Реставрации», выявляет отношения форм собственности и политических институтов, факты зависимости форм общественного устройства от экономической структуры. Об этом свидетельствует и указатель ко второй тетради: «Собственность и ее следствия. Варфоломеевская ночь частной собственности. Конфискация имущества духовенства и преимущественное удовлетворение государственных кредиторов. Максимум и система террора. Взаимосвязь собственности с барством и холопством. Собственность как условие права голоса. Имущество и собственность» [2, с. 116].

О характере аналитической работы Маркса с историческим текстом можно судить по такому примеру: делается пространная выписка из работы Людвига с характеристикой мероприятий якобинцев по обобществлению собственности: ночь 4 августа «была переходом от такого порядка вещей, где все принадлежало отдельным лицам, к такому порядку, где все должно было принадлежать государству. Эта ночь изменила облик монархии. Она сделала всех французов равными; каждый мог достичь любых, самых высоких положений, приобрести собственность и заниматься ремеслом; эта ночь, наконец, была такой же важной революцией, как и восстание 14 июля, следствием которого она являлась. Она сделала народ хозяином в обществе, где он стал править, и подготовила новую конституцию, упразднив старую» [2, с. 85]. За этими строками следует замечание Маркса: «Это конфискация имущества духовенства, главным образом для того, чтобы избежать государственного банкротства, «чтобы удовлетворить государственных кредиторов», отсюда: «государственные бумаги с принудительным оборотом - ассигнации» (в этом - большое противоречие, благодаря тому, что, с одной стороны, частная собственность неприкосновенна, с другой - является частной собственностью, приносимой в жертву)» [2, с. 85].

Маркс переосмысливает связь исторических фактов, предложенных Людвигом. Во-первых, частная собственность не может быть просто устранена переворотом или юридическим актом. Во-вторых, любое, даже революционное правительство вынуждено вносить конституционные изменения, учитывая экономическую сторону общественных отношений. Частная собственность, таким образом, способна изменить ход революции и процесс общественной перестройки. Весь текст «Крейцнахских тетрадей» - как бы ряд следующих одно за другим подобных аналитико-исторических исследований, заканчивающихся обобщениями социально-философского содержания.

Характерно, что выписки из исторических работ перемежаются выписками из социально-философских произведений, и таким образом, философский ряд доказательств непрерывно сравнивается с выводами исторического обобщения. Например, во второй тетради за выписками из Э. Людвига, П. Дарю, Ш. Дакретеля следуют подробные выписки из «Общественного договора» Ж.-Ж. Руссо, и далее, после выписок из Ж.Ж. Байеля и Г. Броугема - трактат Монтескье «О духе законов». В самом предметном указателе к первой и второй тетрадям эта связь исследований отношений собственности в ее исторических формах с критикой существующих социальнофилософских концепций общественного устройства просматривается в самом смещении предмета анализа с исследования собственности у Людвига к исследованию отношений права у Руссо (11-15 пункты в предметном указателе к I и II тетрадям).

Направление мысли Маркса проясняет, в частности, его работа с текстом работы Руссо «Общественный договор». Содержание выписанного текста свидетельствует о внимании Маркса к противоречиям в концепции Руссо, которые как раз и акцентируются выписками. Руссо утверждает, что самое естественное общество - это семья, и в то же время декларирует принцип общей воли как центральный принцип любой государственности: «Каждый из нас передает в общее достояние и ставит под высшее руководство общей воли свою личность и все свои силы, и в результате для нас всех вместе каждый член превращается в нераздельную часть целого» [3, с. 472]. Из текста Руссо Марксом выписываются подробно все условия так называемого естественного права - права «теперешних королей» (замечание Маркса). «Общественное соглашение» уничтожает неравенство лишь формально. Здесь Марксом отмечается следующая фраза Руссо: «При дурных правлениях это равенство лишь кажущееся и обманчивое, оно служит лишь для того, чтобы бедняка удерживать в его нищете, а за богачом сохранить все то, что он присвоил» [3, с. 475]. Собственные аналитические выводы Маркса, сделанные на основании работы с первоисточниками, сопоставляются им на страницах «Крейцнахских тетрадей» с практикой анализа общественных отношений прусского государства и закрепляются анализом социально-философских систем французских просветителей.

В «Крейцнахских тетрадях» формируется взгляд Маркса на историю как на триединый процесс: развитие исторических форм владения в тесной связи их с развитием форм сословных привилегий и форм государствен- 
ного управления. Результатом исторического развития является, во-первых, отделение государства от общественной жизни и уничтожение первичной исторической целостности индивида, который не участвует в буржуазном обществе ни в политической, ни в социальной жизни. Во-вторых, государство все в большей степени становится государством частной собственности.

Так исторические исследования Маркса подводят его к необходимости рассмотрения в дальнейшем различных форм отчуждения в буржуазном обществе. Это видно уже во второй части работы «К критике гегелевской философии права»: «Наше время, цивилизация, совершает ошибку... Оно отделяет от человека, - как нечто только внешнее, материальное, - его предметную сущность. Оно не считает содержание человека его истинной действительностью» [4, с. 313].

С формированием нового взгляда на историю изменяется и категориальный аппарат ее реконструкции. Маркс, цитируя, уточняет некоторые положения историков, схватывая действительный смысл исторического процесса. В частности, в тексте выписок из «Истории Франции» Хайнриха положения автора заостряются выявлением экономической сущности связей исторических фактов. Так, в «финансовых операциях» (Finanzoperationen) Маркс усматривает финансовые спекуляции (Finanzspeculationen), в сделках (Geschäfte) - peальную «власть, силу» (Gewalt).

Прерывая цитирование Ранке, Маркс делает очень ценное для понимания его исторической концепции замечание относительно диалектичности исторического процесса и его метафизического понимания в духе «политической теологии»: «При Людовике XVIII конституция /существовала/ милостью короля (октроированная хартия короля), при Луи-Филиппе - король милостью конституции (октроированная королевская власть). Вообще, мы можем заметить, что превращение субъекта в предикат, а предиката - в субъект, перестановка определяющего и определяемого, то и дело случались в последней революции. Но не только на революционной стороне. Король делает закон (старая монархия). Закон делает короля (новая монархия). Точно так же - с конституцией. То же - и реакционеры. Майорат есть закон государства. Государство желает закон майората. Поэтому, делая субъектом моменты государственной идеи, а ранее существовавшие государства (die alten Staatsexistenzen) - предикатом, между тем как в исторической действительности дело обстоит наоборот, идея государства была скорее предикатом его существования, он (Гегель) выражает лишь всеобщий характер эпохи, ее политическую теологию. Здесь происходит то же самое, что и с его философски-религиозным пантеизмом. Все формы неразумного (Unvernunft) становятся благодаря этому формами разума (Vernunft). Однако в принципе здесь сделаны определяющими (Bestimmenden): в религии - разум, в государстве - идея государства (Staats-idee). Эта метафизика есть метафизическое выражение реакции, чей старый мир (есть) для нее истина нового мировоззрения (...der Reaction, der aften Welt als Wahrheit der neuen Weltanschauung...)» $[2$, c. 181].

Употребление термина «die alten Staatsexistenzen» в оригинале свидетельствует о том, что Маркс оборачивает гегелевский метод не абстрактно, а применительно к формирующимся представлениям об историческом процессе как реальности и способах его моделирования в границах философского метода, представлениям, согласно которым материалистическая критика не выбирает из двух свойств государства - одно, существенное, и не возводит его в ранг идеи государства, а выводит из реального государства его существенные характеристики (различие между таксономической категорией - идеей государства - и таксономическим объектом - реальным государством) [5].

Сопоставление Марксом действительной, исторической, и мнимой, извращенной диалектики, возведенной в ранг политической теологии, предваряет его будущую, более конкретную оценку идеологии как превращенной теологической формы действительной связи между государством в его правовых и политических формах и частной собственностью: «Ни одному из этих философов и в голову не приходило задать себе вопрос о связи немецкой философии с немецкой действительностью, о связи их критики с их собственной материальной средой» $[6$, с. 18].

С исследованием исторических форм частной собственности в тетрадях тесно связаны исследования условий возникновения классов и государственно-правовые проблемы. Маркс обращает внимание на иерархию слоев и классов, образующую род пирамиды, вершиной которой является король, выступающий первоначально как военачальник, вождь и высший сюзерен. Он же является первым земельным собственником рейха. Фундамент пирамиды - крепостные крестьяне с прослойкой независимых земельных собственников, которая при прогрессивном развитии укрепляется, и над этими классами возвышается дворянское сословие. Отмечаются также процессы самообразования городских коммун, как результат активности буржуазии. Из книг Дж. Лингардта по истории Англии выписываются места о возникновении городов и росте их мощи. В первой тетради из книги Хайнриха выписываются сведения о происхождении, составе и способе функционирования французского парламента. Из книги Т. Гамильтона «Люди и нравы в Соединенных Штатах Америки» делаются выписки о глубоких социальных конфликтах буржуазно-демократической республики. 
В ходе работы с историческими произведениями происходит уточнение исходных позиций Маркса в вопросе о субъекте исторического действия, о «качестве» исторического знания, о критериях исторического прогресса. Выявив действительную детерминацию в отношении «гражданское общество - государство», Маркс переходит к изучению структуры гражданского общества. Итогом первого этапа процесса интеграции социально-философского знания в границах материалистического понимания истории явилась модель гражданского общества - общественной структуры, основание которой составляет частная собственность и соответствующие ей политические формы. В качестве рабочей принята модель общественного прогресса как движение к восстановлению естественных прав труженика и реализации принципа целостности и универсальности в развитии человека. Дана оценка современных Марксу буржуазных общественных отношений как несоответствующих природе человека и потому преходящих. «Крейцнахскими тетрадями» завершается первый теоретический этап становления материалистической социально-философской концепции. На этом этапе формируются основания нового системного подхода. Маркс теоретически оформляет свое отношение к прусскому государству, отвергая принцип этического регулятива как принцип свободы, а вместе с ним - принципы систематизации общественной структуры, основанные на методе синтеза противоречий в высшем понятии. Основанием для отбрасывания принципа общественного договора стали как противоречия, вскрытые Марксом в социальной практике, так и системные идеи Руссо и Гегеля.

\section{ЛИТЕРАТУРА}

1. Вайнштейн 0.Л. Историография средних веков в связи с развитием исторической мысли от начала средних веков до наших дней. - М., Л.: Государственное социально-экономическое изд-во, 1940. - 375 с.

2. Marx K. Historisch politische Notizen (Kreuznacher Hefte 1-5) // Marx K., Engels F. Gesamtausgabe. - Berlin: Dietz Verlag, 1981. - 4 Abteilung: Exzerpte. Kotizen. Marginalien, Bd.2.

3. Маркс К. Выписки из «0бщественного договора» Жан-Жака Руссо // Ж.-Ж. Руссо. Трактаты. - М.: Наука, 1969. - 704 с.

4. Маркс К. К критике гегелевской философии права // Маркс К., Энгельс Ф. Соч. - 2-изд. Т. 1. - М.: Политиздат, 1955.

5. Израитель В.Я. Проблемы формационного анализа общественного развития. - Горький: Волго-Вят. кн. изд-во, 1975. - 191 с.

6. Маркс К., Энгельс Ф. Немецкая идеология // Соч. - 2-е изд. Т. 3. - М.: Политиздат, 1955. 